\title{
Distribution of Elite Students in Vietnam Revealed by National Olympiads
}

\author{
Duy Nghia Pham (1) \\ University of the Basque Country, Spain \\ nghiapham@yandex.com
}

23 February $2020^{*}$

\begin{abstract}
Vietnamese National Olympiads 2010-2020 has awarded elite students more than 24,000 prizes. Provinces in the Red River Delta and the North Central Coast with their high schools for the gifted led the country in the number of elite students and the proportion of highest achievers. In comparison with social science test subjects, natural science subjects were more characterized by younger students and male students and less represented by ethnic minority students.
\end{abstract}

\section{Introduction}

National Olympiads [Kỳ Thi Chọn Học Sinh Giỏi Quốc Gia Trung Học Phổ Thông] are organized annually by the Ministry of Education and Training, Vietnam (MoET) to identify and foster talented students at the upper secondary level. A majority of participants are grade-12 students, although candidates in grade 10 and grade 11 are allowed to compete. Each student can only take one of 12 test subjects comprising Mathematics, Informatics, Physics, Chemistry, Biology, Literature, History, Geography, English, French, Russian, and Chinese.

Students are delegated by administrative contest teams which are 63 Provincial/Municipal Departments of Education and Training (hereinafter "provincial teams"), seven universities having affiliated high schools for the gifted (i.e. Vietnam National University, Hanoi (VNU Hanoi), Vietnam National University, Ho Chi Minh City (VNU HCM), Hanoi National University of Education (HNUE), Ho Chi Minh City University of Education (HCMUE), Vinh University (Vinh Uni), Hue University (Hue Uni), Tan Tao University (TTU)), and the Ministry-affiliated ethnic minority boarding school (VCVB) [Trường Phổ thông Vùng Cao Việt Bắc]. For each subject, each contest team can nominate six students or up to ten students if the team performed well in the last two years (MoET 2014). The Ha Noi team is an exception with 12 to 20 students due to its administrative boundary adjustment in 2008 that subsumed former Ha Tay province into the capital. Nominated students often originate from high schools for the gifted or specialized classes of ordinary high schools and they had passed a series of rigorous local contests to be qualified (Le and Le 2010).

According to MoET (2014), less than $50 \%$ of contestants win a prize that is classified as first, second, third, or consolation. Among awarded prizes, first prizes must not exceed $5 \%$ and the total of first, second, and third prizes must be less than $60 \%$. Awarded students are given the privilege of direct entry into nationwide universities and colleges. Highest achievers also have chances to be the representatives of Vietnam in Regional and International Olympiads.

This article reports the distribution of talented high school students in Vietnam based on the result of the National Olympiads over 11 years (2010-2020).

\footnotetext{
*Updated 02 May 2020.
} 
Table 1: Overall team ranking and rankings by subject 2010-2020.

\begin{tabular}{|c|c|c|c|c|c|c|c|c|c|c|c|c|c|}
\hline Team & Overall & Mathematics & Informatics & Physics & Chemistry & Biology & Literature & History & Geography & English & French & Russian & Chinese \\
\hline VNU Hanoi & 1 & 1 & 1 & 1 & 2 & 1 & NA & NA & NA & 3 & 7 & 9 & 3 \\
\hline Nghe An & 2 & 2 & 3 & 2 & 1 & 6 & 3 & 5 & 1 & 8 & 11 & 7 & NA \\
\hline Nam Dinh & 3 & 7 & 6 & 4 & 3 & 12 & 4 & 4 & 3 & 12 & 4 & 1 & NA \\
\hline Hai Duong & 4 & 5 & 8 & 12 & 8 & 3 & 7 & 2 & 4 & 14 & 6 & 4 & NA \\
\hline Vinh Phuc & 5 & 6 & 11 & 7 & 4 & 3 & 10 & 1 & 2 & 15 & 10 & NA & NA \\
\hline VNU HCM & 6 & 9 & 3 & 5 & 6 & 11 & 14 & NA & NA & 1 & NA & NA & NA \\
\hline Hai Phong & 7 & 8 & 5 & 12 & 11 & 13 & 1 & 19 & 12 & 4 & 1 & 6 & 1 \\
\hline Ha Tinh & 8 & 3 & 9 & 6 & 21 & 2 & 11 & 7 & 5 & 9 & 5 & NA & NA \\
\hline Ha Noi & 9 & 17 & 10 & 10 & 12 & 7 & 12 & 12 & 25 & 5 & 3 & 3 & NA \\
\hline Thanh Hoa & 10 & 10 & 14 & 3 & 13 & 8 & 9 & 8 & 11 & 19 & 23 & 10 & NA \\
\hline HNUE & 11 & 4 & 2 & 18 & 19 & 3 & 19 & NA & 23 & 10 & NA & NA & NA \\
\hline Bac Giang & 12 & 23 & 18 & 9 & 13 & 21 & 2 & 9 & 16 & 25 & 19 & NA & 7 \\
\hline Phu Tho & 13 & 11 & 24 & 24 & 17 & 15 & 7 & 3 & 9 & 21 & 17 & NA & NA \\
\hline Ha Nam & 14 & 12 & 24 & 15 & 22 & 20 & 6 & 10 & 5 & 40 & NA & 5 & NA \\
\hline Quang Ninh & 15 & 20 & 7 & 23 & 27 & 25 & 19 & 14 & 8 & 16 & 8 & NA & 8 \\
\hline Da Nang & 16 & 12 & 17 & 11 & 9 & 17 & 15 & 28 & 27 & 11 & 15 & NA & NA \\
\hline Thua Thien Hue & 17 & 23 & 23 & 14 & 22 & 9 & 18 & 23 & 18 & 6 & 9 & NA & NA \\
\hline Ho Chi Minh & 18 & 26 & 15 & 20 & 5 & 13 & 34 & 30 & 34 & 2 & 2 & NA & 2 \\
\hline Thai Nguyen & 19 & 44 & 32 & 33 & 24 & 10 & 5 & 5 & 13 & 23 & 15 & 2 & 4 \\
\hline Thai Binh & 20 & 14 & 34 & 18 & 25 & 18 & 12 & 12 & 7 & 18 & NA & NA & NA \\
\hline Bac Ninh & 21 & 18 & 19 & 16 & 10 & 23 & 16 & 17 & 14 & 30 & NA & NA & NA \\
\hline Binh Phuoc & 22 & 23 & 20 & 8 & 7 & 18 & 29 & 15 & 9 & 37 & NA & NA & NA \\
\hline Ninh Binh & 23 & 26 & 13 & 17 & 26 & 23 & 23 & 11 & 19 & 27 & 11 & 11 & NA \\
\hline Hung Yen & 24 & 16 & 15 & 21 & 15 & 26 & 23 & 17 & 15 & 29 & NA & NA & NA \\
\hline Dong Nai & 25 & 29 & 11 & 33 & 16 & 16 & 25 & 36 & 36 & 12 & NA & NA & NA \\
\hline Hoa Binh & 26 & 30 & 27 & 29 & 28 & 28 & 28 & 21 & 26 & 44 & NA & 8 & 6 \\
\hline Quang Binh & 27 & 15 & 45 & 25 & 36 & 33 & 19 & 16 & 17 & 28 & NA & NA & NA \\
\hline Ba Ria - Vung Tau & 28 & 22 & 30 & 28 & 29 & 27 & 22 & 36 & 35 & 7 & NA & NA & NA \\
\hline Lao Cai & 29 & 34 & 30 & 39 & 41 & 29 & 16 & 27 & 20 & 31 & NA & NA & 5 \\
\hline Dak Lak & 30 & 39 & 21 & 27 & 19 & 44 & 29 & 29 & 29 & 38 & 20 & NA & NA \\
\hline Binh Dinh & 31 & 20 & 36 & 26 & 18 & 31 & 38 & 32 & 46 & 20 & NA & NA & NA \\
\hline VCVB & 32 & NA & NA & NA & NA & 34 & 45 & 19 & 21 & NA & NA & NA & NA \\
\hline Vinh Uni & 33 & 18 & 26 & 35 & 31 & 47 & NA & NA & NA & 31 & NA & NA & NA \\
\hline Lam Dong & 34 & 42 & 22 & 29 & 32 & 29 & 46 & 36 & 37 & 26 & 18 & NA & NA \\
\hline Tuyen Quang & 35 & 34 & 42 & 42 & NA & 32 & 32 & 22 & 22 & NA & NA & NA & NA \\
\hline Quang Nam & 36 & 28 & 42 & 32 & 33 & 34 & 37 & 23 & 28 & 47 & NA & NA & NA \\
\hline Yen Bai & 37 & 42 & 37 & 21 & 37 & 39 & 36 & 25 & 23 & 45 & NA & NA & NA \\
\hline Son La & 38 & NA & NA & 44 & NA & NA & 26 & 35 & NA & NA & NA & NA & NA \\
\hline Dien Bien & 39 & NA & NA & 36 & 46 & NA & 27 & 30 & 42 & NA & NA & NA & NA \\
\hline Khanh Hoa & 40 & 39 & 33 & 31 & 34 & 46 & 56 & 49 & 50 & 17 & 13 & NA & NA \\
\hline Quang Tri & 41 & 33 & 28 & 39 & 40 & 49 & 32 & 42 & 31 & 39 & NA & NA & NA \\
\hline Binh Duong & 42 & NA & 35 & NA & 43 & 40 & 38 & 42 & 33 & 31 & NA & NA & NA \\
\hline Can Tho & 43 & 48 & 28 & 43 & 43 & 37 & 52 & 52 & 42 & 22 & 14 & NA & NA \\
\hline Dong Thap & 44 & 34 & 37 & 45 & 47 & 22 & 34 & 55 & 37 & NA & NA & NA & NA \\
\hline Lang Son & 45 & 46 & NA & 45 & 37 & 40 & 42 & 26 & 30 & 50 & NA & NA & NA \\
\hline Ben Tre & 46 & 34 & 39 & 39 & 43 & 40 & 56 & 49 & 47 & 31 & 21 & NA & NA \\
\hline Phu Yen & 47 & 32 & NA & 38 & 37 & NA & 43 & 54 & 45 & 31 & NA & NA & NA \\
\hline Ha Giang & 47 & NA & NA & NA & NA & NA & 40 & NA & NA & NA & NA & NA & NA \\
\hline Quang Ngai & 49 & 30 & 45 & 36 & 30 & 51 & 46 & 40 & 37 & 46 & NA & NA & NA \\
\hline Tien Giang & 50 & NA & 41 & NA & NA & 38 & 56 & NA & 44 & 41 & 21 & NA & NA \\
\hline Gia Lai & 51 & 46 & NA & 45 & 42 & 34 & 29 & 46 & 40 & 41 & NA & NA & NA \\
\hline Kon Tum & 52 & 44 & NA & 48 & 34 & 45 & 43 & 33 & 32 & 48 & NA & NA & NA \\
\hline Cao Bang & 53 & NA & NA & NA & NA & NA & 49 & 33 & 41 & NA & NA & NA & NA \\
\hline HCMUE & 54 & NA & NA & NA & NA & NA & 62 & NA & NA & 24 & NA & NA & NA \\
\hline Lai Chau & 55 & NA & NA & NA & NA & NA & 40 & 42 & 49 & NA & NA & NA & NA \\
\hline Binh Thuan & 56 & 34 & NA & NA & NA & 43 & 56 & NA & 47 & NA & NA & NA & NA \\
\hline Ca Mau & 57 & 49 & NA & NA & 48 & NA & 49 & 36 & 50 & NA & NA & NA & NA \\
\hline An Giang & 58 & NA & NA & NA & NA & NA & 52 & NA & NA & 41 & NA & NA & NA \\
\hline Vinh Long & 59 & 39 & NA & NA & NA & 48 & 62 & 41 & NA & 49 & NA & NA & NA \\
\hline Tay Ninh & 60 & 51 & 47 & NA & NA & NA & 46 & 48 & NA & NA & NA & NA & NA \\
\hline Tra Vinh & 61 & NA & NA & NA & NA & NA & 49 & NA & NA & NA & NA & NA & NA \\
\hline Long An & 62 & 52 & NA & NA & NA & 49 & 62 & 52 & NA & 31 & NA & NA & NA \\
\hline Kien Giang & 63 & NA & 39 & NA & NA & NA & 60 & 49 & 50 & NA & NA & NA & NA \\
\hline Dak Nong & 64 & NA & NA & NA & NA & NA & 60 & 42 & 53 & NA & NA & NA & NA \\
\hline Hau Giang & 65 & NA & NA & NA & NA & NA & 52 & NA & NA & NA & NA & NA & NA \\
\hline Ninh Thuan & 65 & NA & NA & NA & NA & NA & 52 & NA & NA & NA & NA & NA & NA \\
\hline Soc Trang & 67 & NA & 42 & NA & NA & NA & 67 & NA & NA & NA & NA & NA & NA \\
\hline Bac Lieu & 68 & 49 & NA & NA & NA & NA & 62 & NA & NA & NA & NA & NA & NA \\
\hline Bac Kan & 69 & NA & NA & NA & NA & NA & 66 & 47 & NA & NA & NA & NA & NA \\
\hline TTU & NA & NA & NA & NA & NA & NA & NA & NA & NA & NA & NA & NA & NA \\
\hline Hue Uni & NA & NA & NA & NA & NA & NA & NA & NA & NA & NA & NA & NA & NA \\
\hline
\end{tabular}

Note: Non-provincial teams are in blue. Teams with less than 11 prizes were not ranked (NA). 


\section{Data Wrangling}

The lists of awarded students from 2010 to 2020 were retrieved from the web portal of MoET (https://en.moet. gov.vn/). Information about a total of 24,151 awards consisting of the participation year, contest team, high school, grade, ethnic, gender, test subject, score, and prize of students was extracted and stored in a data frame (https://doi. org/10.5281/zenodo.3764691). This dataset was then analyzed in $R$ ( $R$ Core Team 2019) using chiefly tidyverse packages (Wickham et al. 2019).

\section{Team Performance}

For each subject, teams were ranked by the number of prizes achieved during 11 years (Table 1). The number of prizes of the Ha Noi team was standardized by dividing in half due to its double size of participants. Teams with less than 11 prizes for the whole period were ignored from ranking as it is likely that they did not join the contest annually. Overall rank was then assigned based on the average of individual subject ranks. The top ten consisted of eight provincial teams - Nghe An, Nam Dinh, Hai Duong, Vinh Phuc, Hai Phong, Ha Tinh, Ha Noi, and Thanh Hoa and two national university teams - VNU Hanoi and VNU Ho Chi Minh. The VNU Hanoi team was ranked first overall and also in Mathematics, Informatics, Physics, and Biology.

The overall rank of provincial teams was combined with the administrative areas data of Vietnam (Hijmans, Garcia, and Wieczorek 2018) in Figure 1. The Red River Delta and the North Central Coast are two regions that hosted highly ranked teams while the performance of teams in the Mekong River Delta was poor.

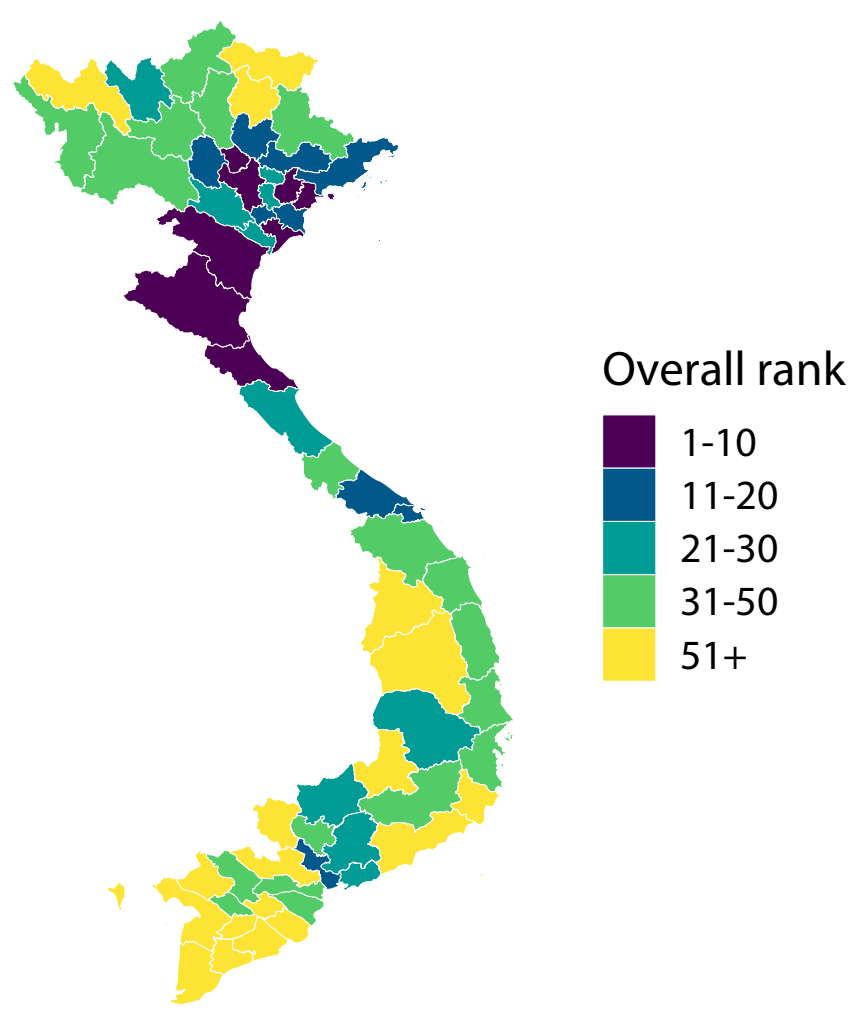

Figure 1: Overall rank of provincial teams displayed on the country map.

The proportion of first prizes was calculated for all teams to explore its correlation with the overall rank (Figure 2). 
Generally, highly ranked teams attained a higher ratio of first prizes, which suggests that prize quantity and quality went hand in hand. Most teams with an above-average proportion of first prizes were in the top 20.

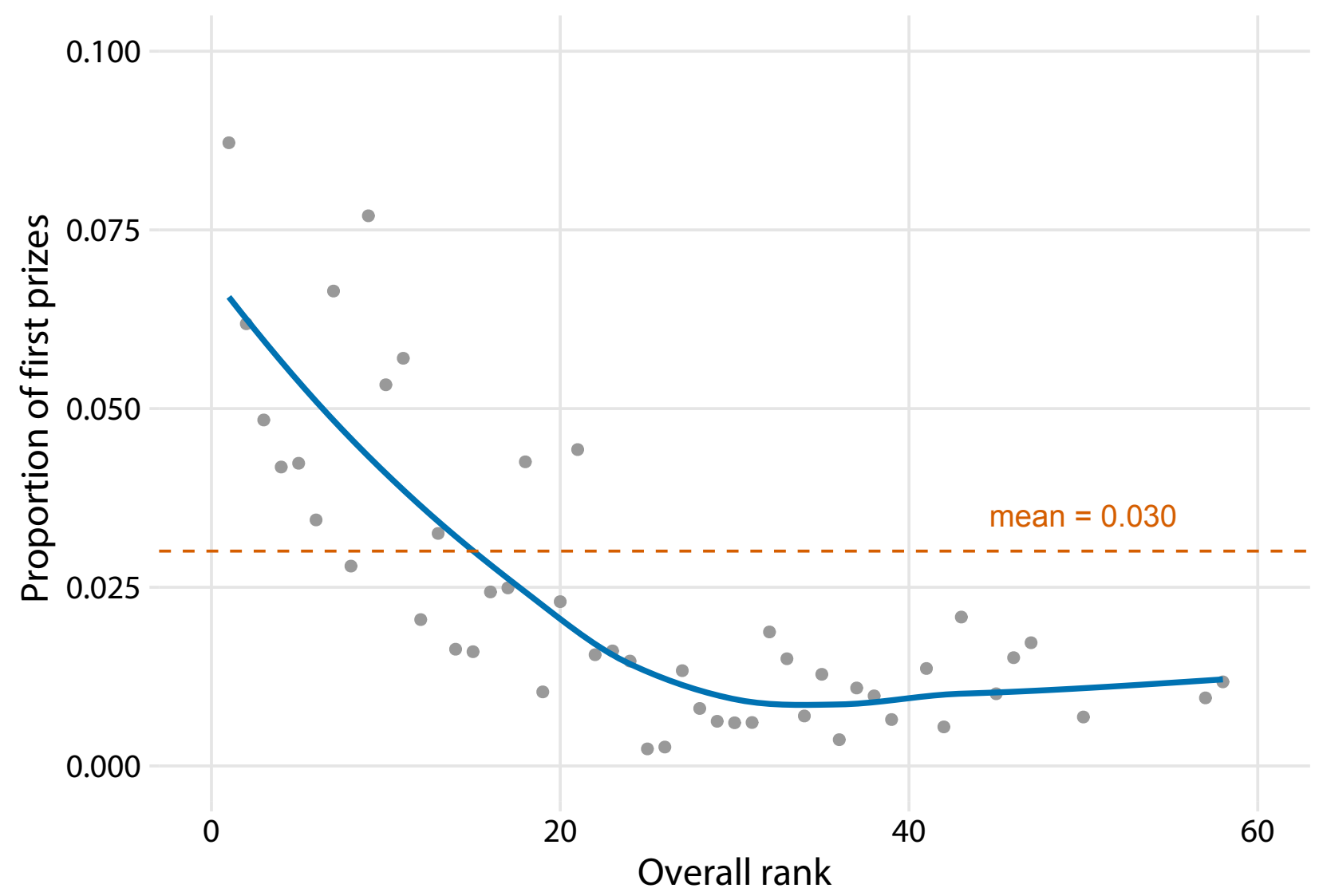

Figure 2: Proportion of first prizes versus overall rank. The solid line corresponds to a LOESS smooth and the dashed line represents the average proportion of first prizes.

Provincial teams are often represented by a group of high schools in the area. The proportion of prizes obtained by the province-leading school was calculated for all provincial teams (Figure 3). Half of teams relied on a school, usually their high school for the gifted, for over $93 \%$ of the prizes. Noteworthy, six schools contributing to $100 \%$ of the prizes of their teams were Phan Boi Chau High School for the Gifted in Nghe An, Le Hong Phong High School for the Gifted in Nam Dinh, Nguyen Trai High School for the Gifted in Hai Duong, Vinh Phuc High School for the Gifted in Vinh Phuc, Bac Giang High School for the Gifted in Bac Giang, Bien Hoa High School for the Gifted in Ha Nam, and Thai Binh High School for the Gifted in Thai Binh; all these teams were in the top 20. Some teams had a few high schools for the gifted that competed internally for prizes so the proportion of prizes achieved by the most dominant one was lower. For example, the Ha Noi team (rank 9) only had the proportion of less than $60 \%$ (data not shown) because its well-known schools such as Hanoi-Amsterdam High School for the Gifted, Nguyen Hue High School for the Gifted, Chu Van An High School all performed well. 


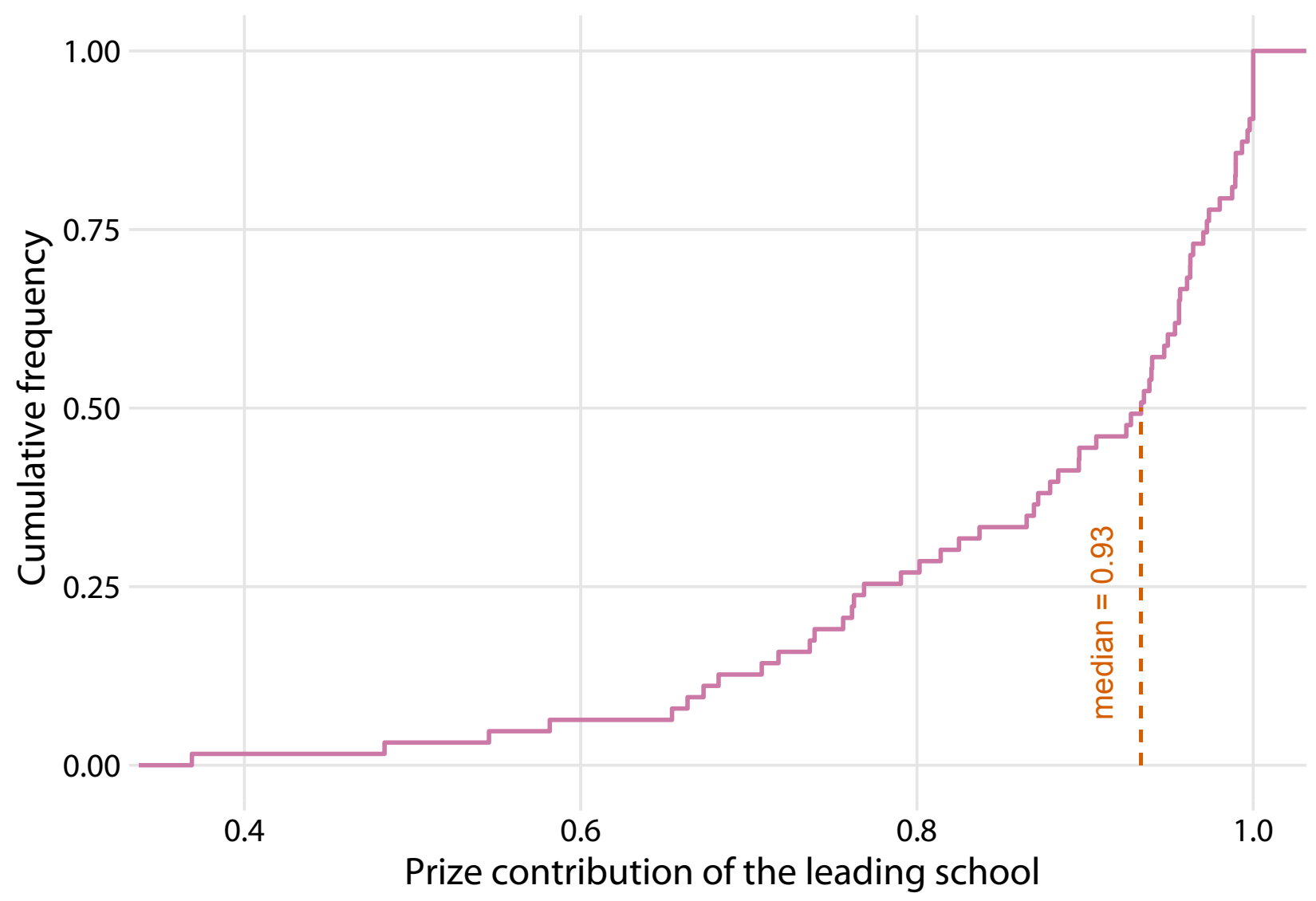

Figure 3: Empirical cumulative distribution function of leading school prize contribution to provincial teams. The dashed line represents the median of leading school prize contribution.

\section{Grade, Gender, and Ethnic Distribution}

The proportion of students in grades 10 and 11 in each test subject is shown in Figure 4. In total, two thirds of awardees were students in grade 12. Young students were relatively more popular in Informatics and Mathematics and rarer in Chinese, Russian, History, Literature, Geography. It might be interpreted that training and learning have more impact on the success in the latter subjects while giftedness is crucial for the former subjects. 


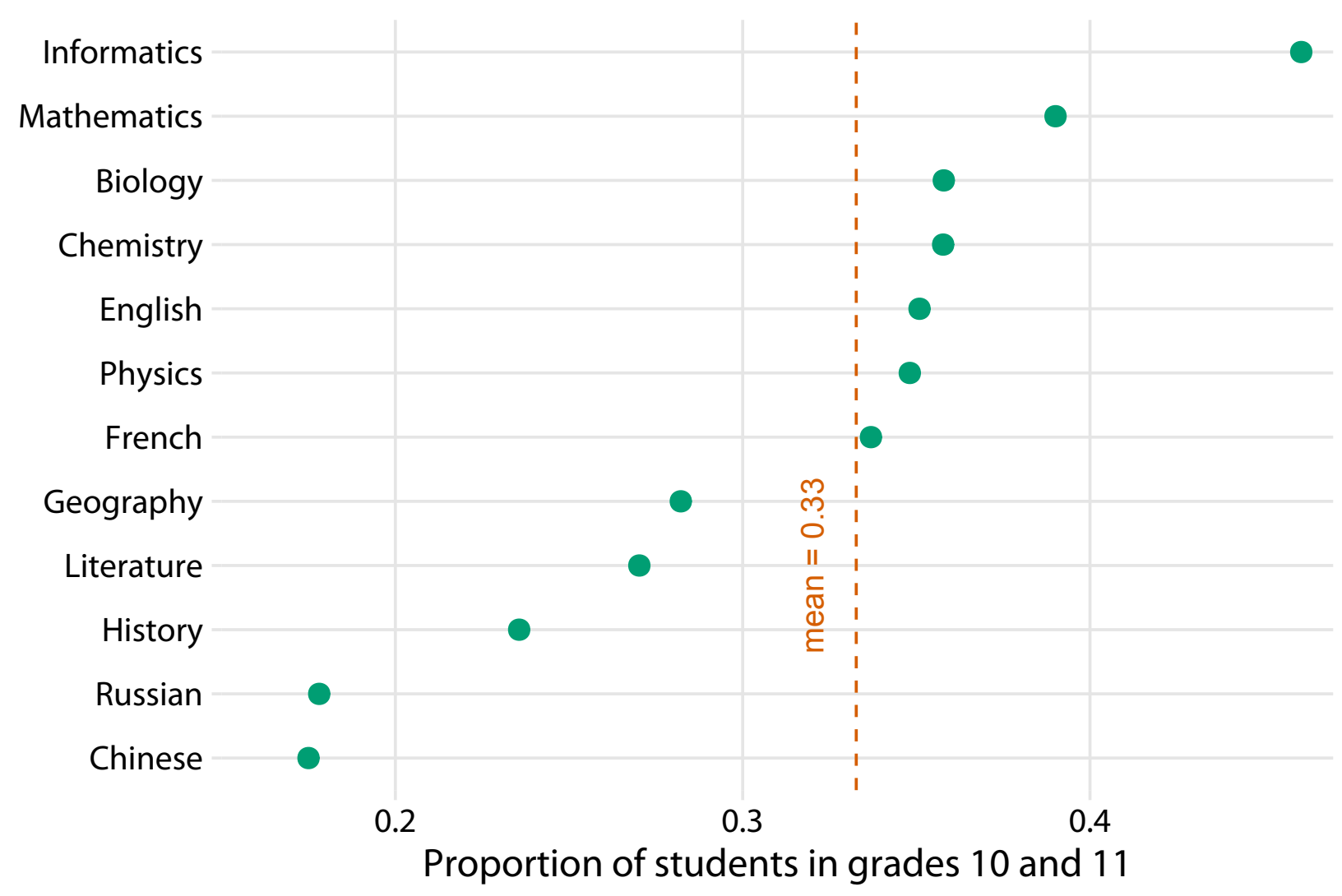

Figure 4: Proportion of grade-10 and grade-11 students in test subjects. The dashed line represents the average proportion of these young students.

The gender distribution of students in each test subject is shown in Figure 5. The male-female ratio was about 49:51 on average. Male students dominated in Informatics, Mathematics, Physics, and Chemistry while female students dominated in Literature, History, Geography, and all language subjects. It does not necessarily imply that male students performed better in natural science subjects and female students did better in social science and language subjects but reflects the gender distribution of students taking the tests. In other words, boys may prefer studying natural sciences over social sciences and languages. 


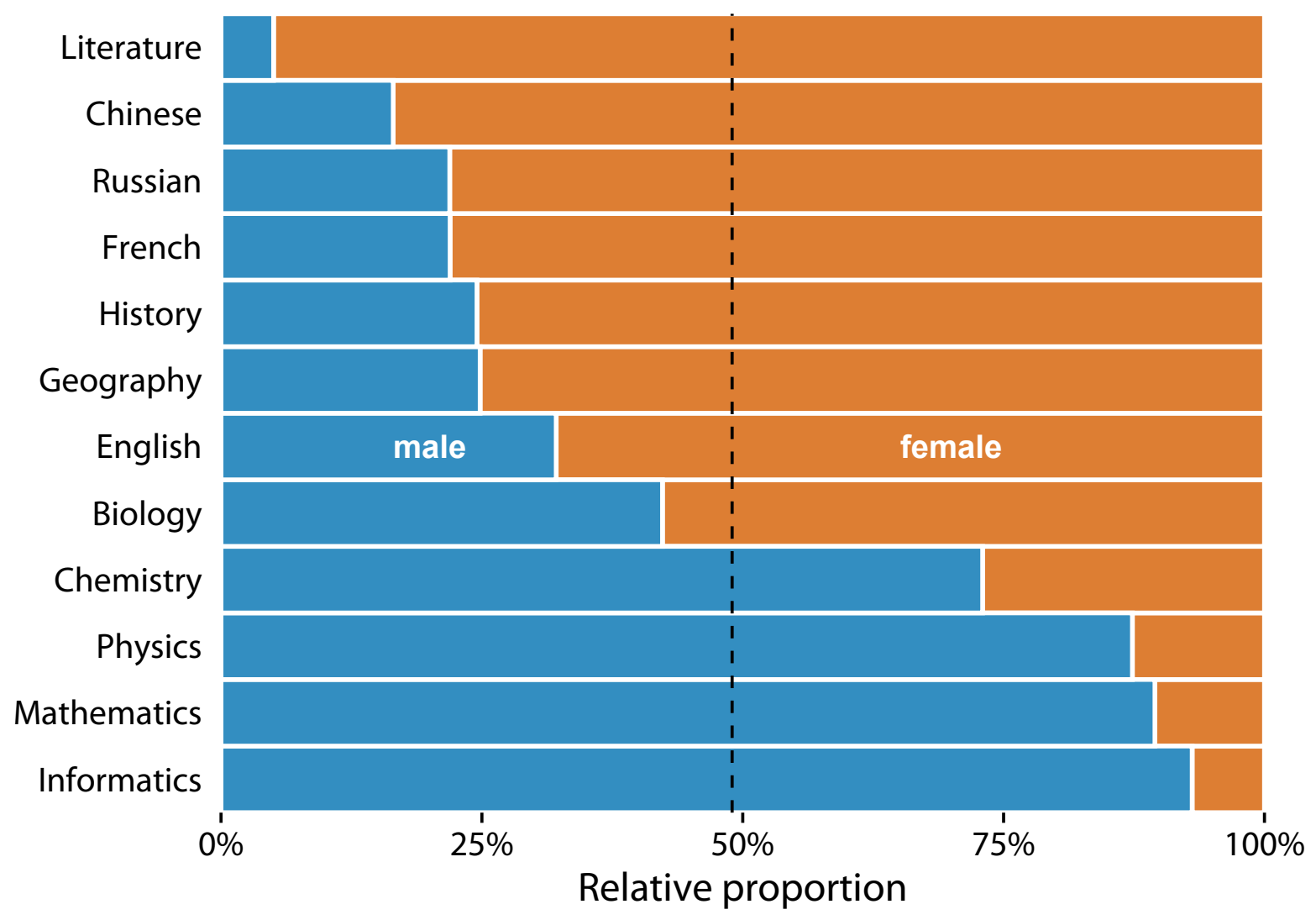

Figure 5: Gender distribution of students in test subjects. The dashed line represents the average distribution.

The proportion of ethnic minority students in each test subject is shown in Figure 6. Students from ethnic minorities accounted for over $4 \%$ of the total prize number. For ethnic minority students, the proportions of prizes in Mathematics, Informatics, Physics, Chemistry, and Biology were in deficit while the proportions of prizes in Literature, History, and Geography were in excess compared to the average. 


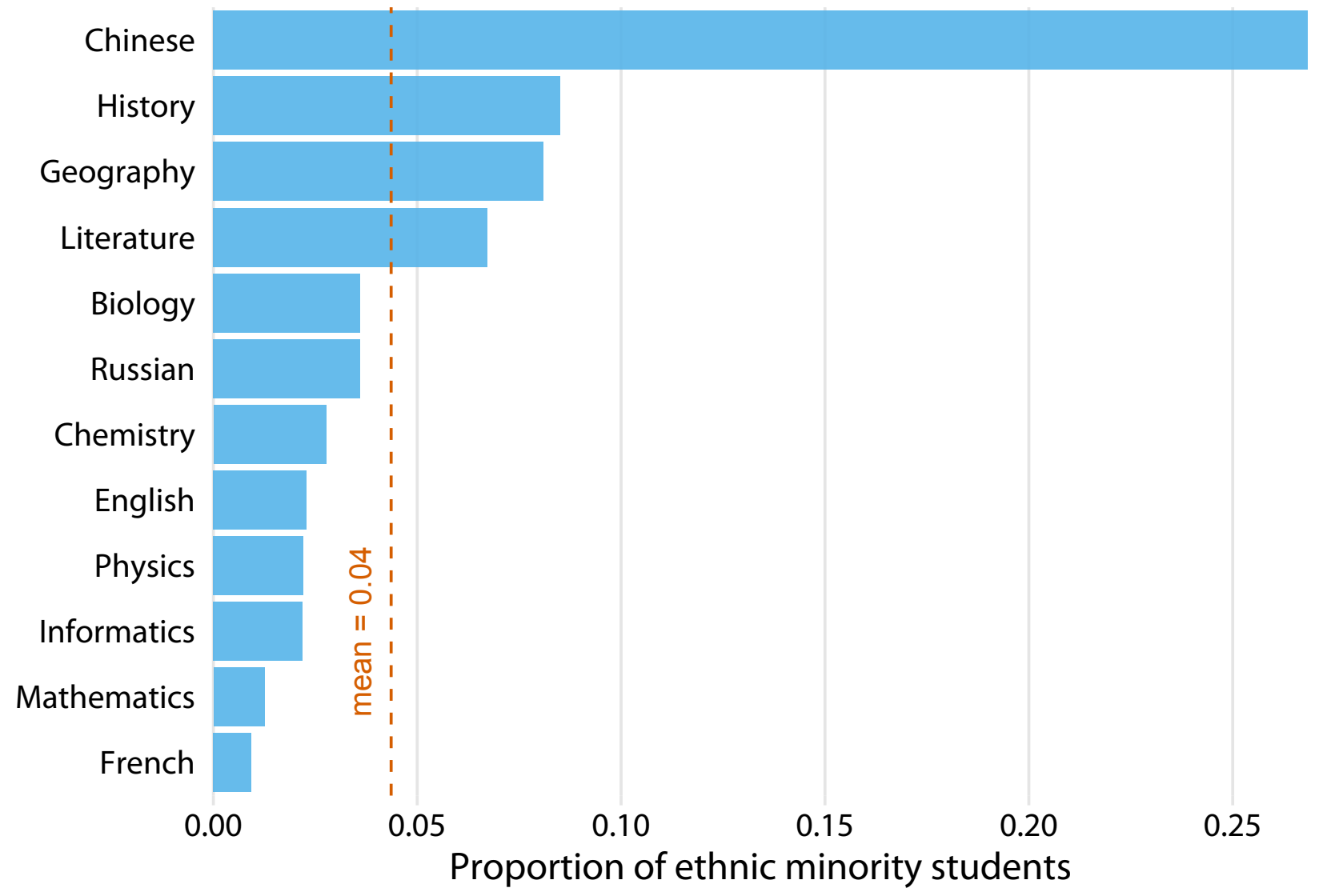

Figure 6: Proportion of ethnic minority students in test subjects. The dashed line represents the average proportion of these students.

\section{Acknowledgments}

The author would like to thank Dr. Quang Hung Luu and Dr. Thi Van Hue Le for their helpful comments on data analysis. Thanks to Ms. Thanh Phuong Nguyen for proofreading the article.

\section{References}

Hijmans, Robert, Nell Garcia, and John Wieczorek. 2018. Global Administrative Areas Database (GADM) Version 3.6. https://gadm.org/.

Le, Hai Chau, and Hai Khoi Le. 2010. Selected Problems of the Vietnamese Mathematical Olympiad (1962-2009). Mathematical Olympiad Series. World Scientific.

MoET. 2014. Quy Chế Thi Chọn Học Sinh Giỏi Cấp Quốc Gia. Government Gazette. Government Office, Vietnam. http://congbao.chinhphu.vn/noi-dung-van-ban-so-22-vbhn-bgddt-12940.

R Core Team. 2019. R: A Language and Environment for Statistical Computing. Vienna, Austria: R Foundation for Statistical Computing. https://www.R-project.org/.

Wickham, Hadley, Mara Averick, Jennifer Bryan, Winston Chang, Lucy McGowan, Romain François, Garrett Grolemund, et al. 2019. "Welcome to the Tidyverse." Journal of Open Source Software 4 (43): 1686. https://doi.org/10. 21105/joss.01686. 